\title{
Konversi Minyak Jelantah Menjadi Green Diesel Dengan Proses Hydrotreating Menggunakan Katalis $\mathrm{NiMo} / \gamma-\mathrm{Al}_{2} \mathrm{O}_{3}$
}

\author{
Roby Adi Nugraha ${ }^{1}$, Ahmad Zikri ${ }^{* 2}$, K.A Ridwan ${ }^{3}$, Aisyah Suci Ningsih ${ }^{4}$ \\ 1,2,3,4 Teknik Energi / Teknik Kimia, Politeknik Negeri Sriwijaya, Indonesia \\ Email: ${ }^{1}$ adinugraha.robby@gmail.com, ${ }^{2}$ ahmad.zikri@ polsri.ac.id
}

\begin{abstract}
Abstrak
Green diesel merupakan senyawa alkana yang setara dengan minyak diesel berbahan dasar minyak bumi. pada penelitian ini digunakan minyak jelantah sebagai bahan baku. Minyak jelantah adalah minyak hasil penggorengan makanan dan mengalami pemanasan terus menerus yang mana pada suhu penggorengan $200^{\circ} \mathrm{C}$ rantai kimia minyak akan terurai. Green diesel diproduksi menggunakan proses katalitik hidrogenasi pada temperatur $430^{\circ} \mathrm{C}$ selama 5 jam. Minyak jelantah sebanyak $2000 \mathrm{ml}$ direaksikan dengan gas hidrogen $\left(\mathrm{H}_{2}\right)$ menggunakan bantuan katalis $\mathrm{NiMo} / \gamma-\mathrm{Al}_{2} \mathrm{O}_{3}$ dengan promotor $\mathrm{K}$ dan $\mathrm{P}$ untuk mempercepat reaksi. Tujuan dari penelitian ini yakni mengetahui tekanan optimum dalam proses pembuatan green diesel menggunakan minyak jelantah, Adapun variasi tekanan hidrogen yang digunakan sebesar 1 bar, 2 bar 3 bar, 4 bar dan 5 bar. Sampel dengan tekanan 4 bar merupakan kondisi optimum pada penelitian ini dan menghasilkan persentase yield sebesar $35,80 \%$. Sifat fisik green diesel yang diperoleh dari penelitian ini, antara lain densitas pada $40^{\circ} \mathrm{C}(773,74-$ $\left.778,96 \mathrm{~kg} / \mathrm{m}^{3}\right)$, viskositas kinematik pada $40^{\circ} \mathrm{C}\left(2,46-2,60 \mathrm{~mm}^{2} / \mathrm{s}\right)$, kadar air $(3249,84-4526,46 \mathrm{ppm})$, titik nyala $\left(46,1-58,1^{\circ} \mathrm{C}\right)$, dan nilai kalor $(42,13 \mathrm{Mj} / \mathrm{kg})$.
\end{abstract}

Kata kunci: Green Diesel, Hidrogen, Katalis, Katalitik Hidrogenasi, Minyak jelantah

\section{Conversion Of Waste Cooking Oil To Green Diesel With Hydrotreating Process Using $\mathrm{NiMo} / \mathrm{\gamma}-\mathrm{Al}_{2} \mathrm{O}_{3}$ Catalyst}

\begin{abstract}
Green diesel is an alkane compound which is equivalent to petroleum-based diesel oil. In this study used cooking oil as raw material. Used cooking oil is the result of frying food and undergoing continuous heating which at a frying temperature of $200^{\circ} \mathrm{C}$ the chemical chain of the oil will decompose. Green diesel is produced using a catalytic hydrogenation process at a temperature of $430^{\circ} \mathrm{C}$ for 5 hours. $2000 \mathrm{ml}$ of used cooking oil was reacted with hydrogen gas $\left(\mathrm{H}_{2}\right)$ using a NiMo/ $-\mathrm{Al}_{2} \mathrm{O}_{3}$ catalyst with $\mathrm{K}$ and $\mathrm{P}$ promoters to accelerate the reaction. The purpose of this study is to determine the optimum pressure in the process of making green diesel using used cooking oil. The variations in hydrogen pressure used are 1 bar, 2 bar, 3 bar, 4 bar and 5 bar. The sample with a pressure of 4 bar is the optimum condition in this study and produces a yield percentage of 35.80\%. The physical properties of green diesel obtained from this study include density at $40^{\circ} \mathrm{C}(773.74-778.96 \mathrm{~kg} / \mathrm{m3})$, kinematic viscosity at $40^{\circ} \mathrm{C}\left(2.46-2.60 \mathrm{~mm}^{2} / \mathrm{s}\right)$, water content $(3249,84-4526.46 \mathrm{ppm})$, flash point (46.1 $\left.58.1^{\circ} \mathrm{C}\right)$, and calorific value $(42.13 \mathrm{Mj} / \mathrm{kg})$
\end{abstract}

Keywords: Green Diesel, Hydrogen, Catalyst, Catalytic Hydrogenation, waste cooking oil

\section{PENDAHULUAN}

Menurut Direktorat Jendral Energi Terbarukan dan Konservasi Energi (2020), Indonesia memiliki kapasitas sumber energi sebesar 70,96 Giga Watt (GW), dari kapasitas energi tersebut 35,36\% dari batubara, 19,36\% dari gas bumi, 34,38\% dari minyak bumi dan EBT ( Energi Baru Terbarukan) hanya sebesar 10,9\%. Ketergantungan terhadap energi fosil inilah yang membuat kakhawatiran pada massa yang akan datang, energi fosil yang akan habis mengharuskan penggunakan energi terbarukan segera ditingkatkan. Salah satu energi terbarukan yang sangat potensial adalah bahan bakar nabati.

Minyak nabati biasa terdiri dari trigliserida yang terikat dalam molekul asam lemaknya dengan 14 hingga 22 atom karbon dalam rantainya. Karena tingkat fungsionalitas yang agak rendah dan kesederhanaannya (gugus karboksilat adalah satu-satunya gugus fungsi yang ada dalam trigliserida) dibandingkan dengan jenis bahan baku 
berbasis biomassa lainnya dan panjang rantai yang sesuai. [1]) salah satu minyak nabati yang sangat potensial adalah minyak jelantah, karena termasuk limbah dan sangat mudah didapatkan.

Minyak jelantah merupakan limbah hasil pengolahan makanan yang mengalami pemanasan lebih dari 3 kali penggorengan. Proses pemanasan yang terus menerus akan berpengaruh terhadap minyak goreng. Pada suhu penggorengan $200^{\circ} \mathrm{C}$ rantai kimia minyak akan terurai. [2]

Transformasi trigliserida menjadi hidrokarbon membutuhkan eliminasi oksigen pada minyak jelantah. Hidroprosesing merupakan salah satu teknologi yang terkenal di bidang industri perminyakan , yang dapat dilakukan dengan teknologi hydrocracking atau dengan teknologi hydrotreating yang lebih ringan. Ketika mereka diterapkan pada hidrokarbon beroksigen, penghilangan oksigen dapat dilakukan dengan dekarboksilasi, dekarbonilasi, atau hidrodeoksigenasi. [3]. Proses hidrotreating minyak nabati mengarah pada produksi bahan bakar cair yang menyerupai bahan bakar solar, dan oleh karena itu biasanya disebut Green diesel atau solar terbarukan.

Pengolahan minyak jelantah menjadi green diesel melalui proses hidrodeoksigenasi, melibatkan katalis untuk mempercepat laju reaksi dan meningkatkan selektivitas. Katalis yang sering digunakan dalam proses hidrodeoksigenasi baik dalam riset dan industri adalah katalis $\mathrm{NiMo} / \gamma-\mathrm{Al}_{2} \mathrm{O}_{3}$, beberapa penelitian aktivasi $\mathrm{NiMo} / \gamma-\mathrm{Al}_{2} \mathrm{O}_{3}$ konversi 46\% [4], Pengembangan Katalis $\mathrm{NiMoP} / \gamma-\mathrm{Al}_{2} \mathrm{O}_{3}-\mathrm{B}_{2} \mathrm{O}_{2}$ konversi 81,45\% [5]

Katalis yang sering digunakan dalam proses hidrodeoksigenasi baik dalam riset dan industri adalah katalis $\mathrm{NiMo} / \gamma-\mathrm{Al}_{2} \mathrm{O}_{3}$, yang perlu diteliti lebih jauh adalah hasil dari proses hidrodeoksigenasi menggunakan katalis $\mathrm{NiMo} / \gamma-\mathrm{Al}_{2} \mathrm{O}_{3}$ dengan variasi tekanan untuk mengetahui performa katalis dalam menghasilkan hidrokarbon terbaharukan

\section{METODE PENELITIAN}

Pada penelitian ini menggunakan seperangkat reaktor Hydrotreating, Furnace (Nabetherm No.295366), Oven, Spatula, Pipet Ukur, Bola Karet, Batang Pengaduk, Kaca Arloji, Mesin Press, Termometer, Labu Ukur,

Bahan yang digunakan pada pembuatan Green Diesel yaitu Ammonium Heptamolybdate Tetrahydrate 0,87 M, Nickel (II) Nitrate Hexahydrate $\left(\mathrm{NiNO}_{3} \cdot 6 \mathrm{H}_{2} \mathrm{O}\right) 2,02 \mathrm{M}$, Gamma Alumina $\left(\gamma-\mathrm{Al}_{2} \mathrm{O}_{3}\right)$, Potasium Karbonat $\left(\mathrm{K}_{2} \mathrm{CO}_{3}\right)$, Asam Fosfat $\left(\mathrm{H}_{3} \mathrm{PO}_{4}\right)$, Minyak Jelantah, Hidrogen $\left(\mathrm{H}_{2}\right)$, Dekstrin, dan Aquadest.

Pada penelitian ini, terdapat beberapa tahapan perlakuan yang dilakukan, diantaranya:

a. Tahap Persiapan Bahan Baku

Minyak jelantah yang merupakan bahan baku diperoleh dari Industri makanan yang berada di sekitar kota Palembang sebanyak \pm 20 liter.

b. Proses Pembuatan Katalis

Katalis yang digunakan pada penelitian ini adalah katalis Nikel Molibdenum dengan support berupa alumina ( $\mathrm{NiMo} / \mathrm{Al}_{2} \mathrm{O}_{3}$ ) dengan penambahan $\mathrm{K}$ dan $\mathrm{P}$ sebagai promotor. Bahan baku yang digunakan pada pembuatan katalis ini adalah Nickel (II) Nitrate Hexahydrate $\left(\mathrm{Ni}\left(\mathrm{NO}_{3}\right)_{2} \cdot 6 \mathrm{H}_{2} \mathrm{O}\right)$ sebagai sumber $\mathrm{Ni}$, Ammonium Heptamolybdate Tetrahydrate $\left(\left(\mathrm{NH}_{4}\right) 6 \mathrm{Mo}_{7} \mathrm{O}_{24} .4 \mathrm{H}_{2} \mathrm{O}\right)$ sebagai sumber Mo,alumina komersial sebagai sumber $\mathrm{Al}_{2} \mathrm{O}_{3}$. Potasium Karbonat $\left(\mathrm{K}_{2} \mathrm{CO}_{3}\right)$ dan Asam Fosfat $\left(\mathrm{H} \mathrm{c} 6-+++{ }_{3} \mathrm{PO}_{4}\right)$ sebagai sumber promotor K dan P. Proses pembuatan katalis ini terdiri dari impregnasi, pengeringan, dan kalsinasi.Reaksi Katalitik Hidrogenasi dalam Reaktor Hidrogenasi

c. Reaksi Katalitik Hidrogenasi dalam Reaktor Hidrogenasi

d. Proses ini dilakukan di dalam reaktor hidrogenasi dengan suhu operasi $430^{\circ} \mathrm{C}$ dan menggunakan katalisNiMo/ $\mathrm{Al}_{2} \mathrm{O}_{3}$ dengan rasio promotor $\mathrm{K} 70 \%$ dan $\mathrm{P} 30 \%$ selama 5,0 jam dengan variasi tekanan hidrogen awal, sebesar 1 bar, 2 bar, 3 bar, 4 bar dan 5 bar.

e. Analisis Produk

- Analisis Sifat Fisik

Analisis sifat fisik pada green diesel bertujuan untuk membandingkan sifat fisik dari green diesel yang dihasilkan dengan diesel olahan minyak bumi . Sifat-sifat fisik yang dianalisa adalah densitas $\left(\mathrm{kg} / \mathrm{m}^{3}\right)$, nilai kalor $(\mathrm{MJ} / \mathrm{kg})$, viskositas kinematik pada $40^{\circ} \mathrm{C}\left(\mathrm{mm}^{2} / \mathrm{S}\right)$, titik nyala $\left({ }^{\circ} \mathrm{C}\right)$, kadar air $(\mathrm{ppm})$.

- Analisis Kuantitatif

Analisis kuantitatif merupakan jumlah produk green diesel yang dihasilkan dan dinyatakan sebagai persentase yield (\%yield).

$$
\text { Yield }=\frac{\text { Massa Green Diesel }}{\text { Massa Umpan }} \times 100 \%
$$

Analisis karakteristik bahan bakar cair yang diuji adalah analisis Densitas (ASTM D-1298), Viskositas (ASTM D-1298), Titik Nyala (ASTM D-93) dan Angka Setana. 


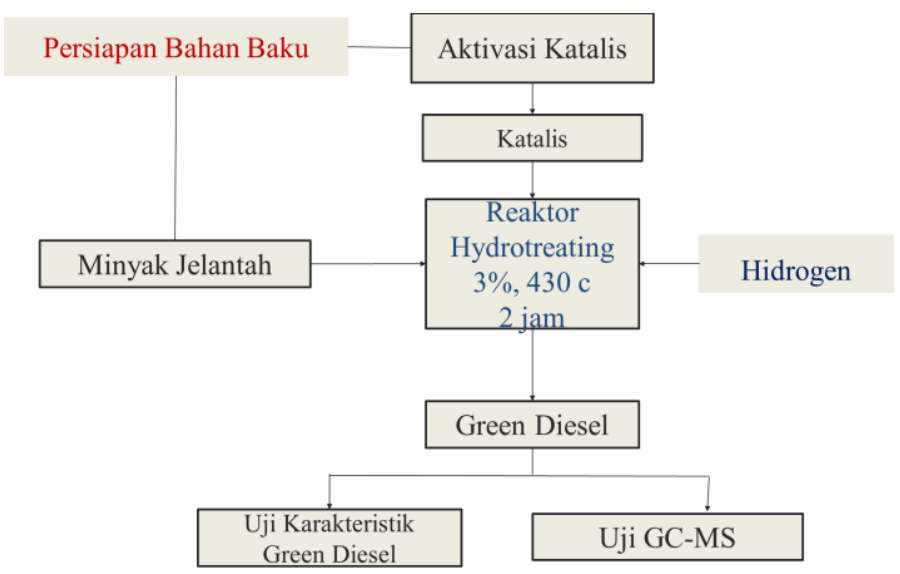

Gambar 1. Diagram Alir Pembuatan Green Diesel

\section{HASIL DAN PEMBAHASAN}

Dari penelitian yang telah dilakukan, didapatkan data hasil pengamatan Green Diesel dengan variasi tekanan hidrogen. Data hasil dan pembahasan adalah sebagai berikut.

\subsection{Pengaruh Tekanan Hidrogen Terhadap Persentase Yield Green Diesel}

Persentase yield merupakan sebuah persentase yang menyatakan jumlah produk yang dihasilkan dari jumlah bahan baku yang diumpankan. Pada penelitian ini, persen yield yang dihitung adalah jumlah green diesel terhadap variasi tekanan hidrogen.

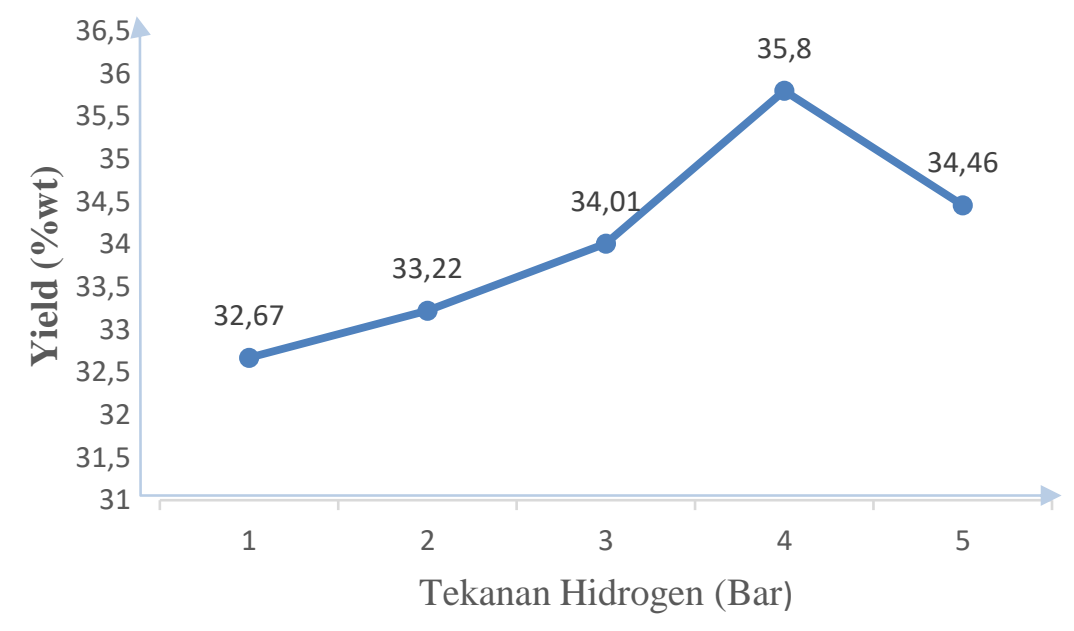

Gambar 2. Pengaruh Tekanan Hidrogen Terhadap Yield (\%Wt) Green Diesel

Dari gambar 2 Dapat dilihat \% yield yang didapatkan dengan variasi tekanan hidrogen, grafik cenderung meningkat dari tekanan 1 bar sampai tekanan 4 bar, pada tekanan 1 bar didapatkan yield sebesar 32,67\% dan pada tekanan 4 bar yield mencapai titik puncak sebesar $35,8 \%$, namun pada tekanan 5 bar yield mengalami penurunan sebesar 34,46\%. Hal ini menunjukan bahwa tekanan hidrogen yang tinggi dapat meningkatkan hidroprecessing katalitik namun kelebihan tekanan hidrogen dapat menghambat proses tersebut. [6]

Selain yield yang rendah penggunaan tekanan rendah pada tekanan 1 bar menyebabkan terbentuknnya coke pada dasar reaktor. Menurut budiarto dalam buku pintar Migas, Coke dapat terjadi karena beberapa hal sebagai berikut: Temperature reaksi yang tidak sesuai (temperatur terlalu tinggi atau umpan minyak terlalu ringan). Hydrogen partial pressure yang rendah (tekanan reaktor atau hydrogen purity recycle gas yang rendah).

Pembentukan coke dapat dihambat dengan cara menaikkan hydrogen partial pressure (tekanan reaktor atau hydrogen purity pada recycle gas). Hal ini menunjukan Hidrogen memainkan peran penting dalam menentukan jalur reaksi untuk hidroprosesing minyak jelantah menjadi senayawa hidrokarbon (alkana). 


\subsection{Pengaruh Tekanan Hidrogen Terhadap Viskositas Green Diesel}

Viskositas merupakan kekentalan dari suatu fluida. Kekentalan didefinisikan sebagai gesekan internal atau gesekan fluida terhadap wadah dimana fluida itu mengalir. Ini ada dalam cairan atau gas, dan pada dasarnya adalah gesekan antar lapisan fluida yang berdekatan ketika bergerak melintasi satu sama lain atau gesekan antara fluida dengan wadah tempat ia mengalir. [7]

Pengukuran suatu viskositas pada minyak green diesel bertujuan untuk mengetahui kekentalan minyak pada suhu tertentu sehingga minyak dapat dialirkan pada suhu tersebut.

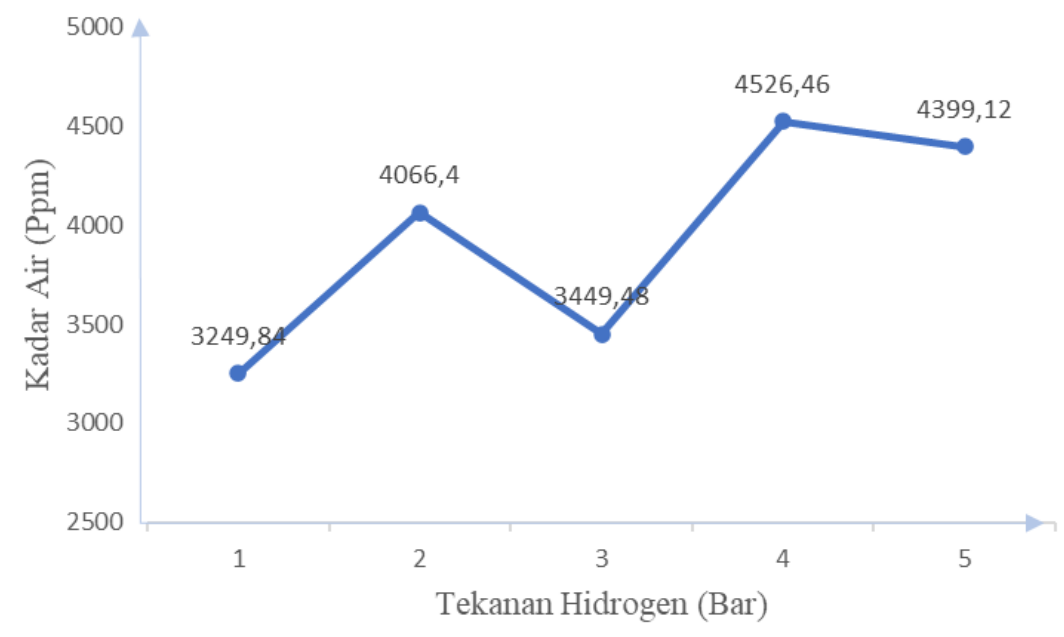

Gambar 3. Pengaruh Tekanan Hidrogen Terhadap Kadar Air Pada Green Diesel

Pada gambar 3 Menunjukan kadar air pada setiap variasi tekanan yakni berkisar antara 3249,84 - 4526,46 ppm, kadar air yang didapatkan tergolong sangat besar dibandingkan dengan Green Diesel European Standard yang mana harus kurang dari 200 ppm. Pada tekanan 1 bar kadar air didapatkan 3249,84 ppm dan mengalami kenaikan dan penurunan pada tekanan 3 bar, kadar air tertinggi pada tekanan 4 bar yakni 3526,46 ppm. Kandungan air yang cukup besar ini disebabkan oleh hasil samping dari proses hidroprocessing, dan pada hidrodeoksigenasi, oksigen yang terlepas dari hasil proses, bereaksi dengan hidrogen sehingga membentuk uap uap air.

\subsection{Pengaruh Tekanan Hidrogen Katalis Terhadap Titik Nyala Green Diesel}

Titik nyala merupakan suhu terendah dimana minyak akan menyala apabila terkena percikan api. Pengukuran titik nyala ini dilakukan menggunakan flash point tester. Semakin tinggi titik nyala, maka semakin mudah proses penyimpananan bahan bakar.

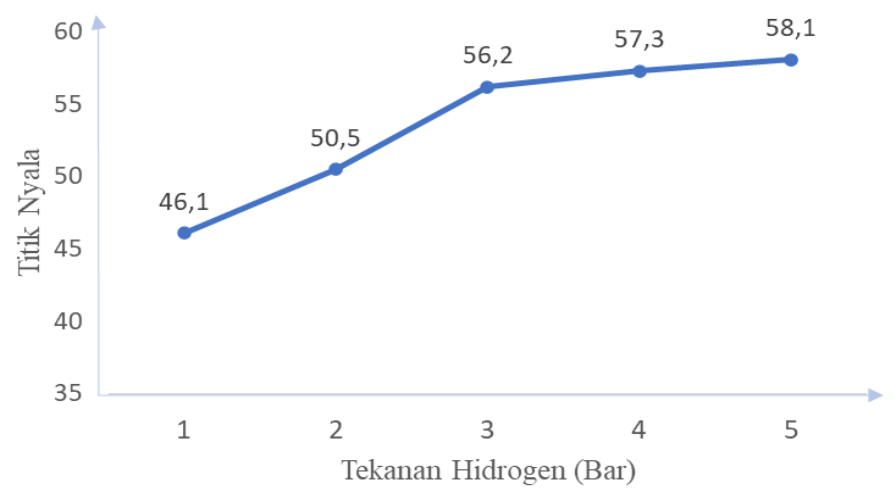

Gambar 4. Pengaruh Tekanan Hidrogen Terhadap Titik Nyala Green Diesel

Dari gambar 4 Dapat dilihat titik nyala dengan variasi tekanan hidrogen berkisar antara 46,1 - 58,1 0C. Menurut Green Diesel European Standards, Green diesel memiliki titik nyala minimal 55 C. hal ini menunjukan 
bahwa pada tekanan 1 bar dan tekanan 2 bar yang berkisar antara $46,1^{\circ} \mathrm{C}$ dan $50,5{ }^{\circ} \mathrm{C}$ belum mencapai standar yang berlaku. Titik nyala yang sesuai didapatkan pada tekanan tinggi yakni pada tekanan 3 - 5 bar, yang mana pada 5 bar adalah titik puncak tertinggi sebesar $58,10 \mathrm{C}$.

Titik nyala meningkat seiring dengan peningkatan tekanan hidrogen, hal ini dikarenakan pada tekanan rendah cenderung akan membentuk fraksi ringan C1-C5 (gas) dan C5-C15 yang mana didominasi gasoline dan kerosine, hal ini lah yang menyebabkan titik nyala cenderung rendah.

\subsection{Pengaruh Tekanan Hidrogen Terhadap Densitas Green Diesel}

Densitas atau Kerapatan merupakan jumlah atau kuantitas dari suatu zat, nilai Kerapatan di pengaruhi oleh temperatur. Semakin tinggi temperatur maka kerapatan suatu fluida semakin berkurang karna disebabkan gaya kohesi dari molekul molekul fluida semakin berkurang. [7]. Densitas merupakan salah satu sifat fisik yang dapat dijadikan indikasi dalam mengetahui jenis produk atau senyawa tertentu.

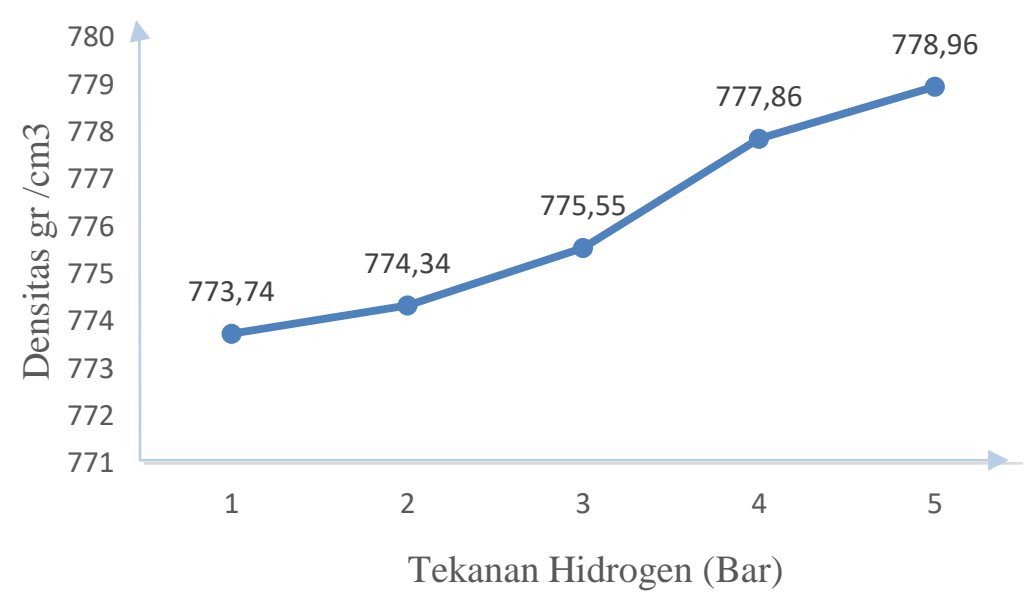

Gambar 4.6 Pengaruh Tekanan Hidrogen Terhadap Densitas Green Diesel

Menurut Green Diesel European Standards, Green diesel memiliki range densitas antara $765-800 \mathrm{~kg} / \mathrm{m}^{3}$ sedangkan pada penelitian ini, densitas produk yang diperoleh berkisar $773,74-778,96 \mathrm{~kg} / \mathrm{m}^{3}$. Densitas produk green diesel pada penelitian ini sudah memenuhi standar yang berlaku. Pada grafik menunjukan kenaikan yang cukup signifikan. pada penggunaan tekanan 1 bar didapatkan densitas sebesar $773,74 \mathrm{~kg} / \mathrm{m}^{3}$ dan pada tekanan yang lebih besar yakni pada tekanan 5 bar didapatkan 778,96 kg/m3. Sehingga dapat dianalisa bahwa semakin besar tekanan yang digunakan semakin besar pula densitas yang didaptakan.

\section{KESIMPULAN}

Kondisi Tekanan optimum pembuatan green diesel menggunakan katalitik hidrogenasi yaitu pada pemakaian katalis $\mathrm{NiMo} / \mathrm{y}-\mathrm{Al}_{2} \mathrm{O}_{3}$ sebanyak 4 bar dalam $2000 \mathrm{ml}$ Minyak Jelantah. Persentase yield maksimum yang diperoleh pada penelitian ini adalah 35,80 \% dengan pemakaian tekanan 4 bar, sedangkan persentase yield minimum diperoleh dari produk green diesel dengan pemakaian tekanan 1 bar yakni sebesar 32,67\%.

Green diesel yang diproduksi pada penelitian ini memiliki sifat fisik seperti Densitas : 773,74-778,96 kg/m, Viskositas Kinematik : 2,47-2,6 mm/s, Kadar Air $: 3249,84-4526,46$ ppm, Titik Nyala : $46,1-58,1{ }^{\circ} \mathrm{C}$

\section{DAFTAR PUSTAKA}

[1] J. Ahmad, A. ul Hasan, T. Naqvi, and T. Mubeen, "A Review on Software Testing and Its Methodology," Manag. J. Softw. Eng., vol. 13, no. 1, pp. 32-38, 2019, doi: 10.26634/jse.13.3.15515.

[1] D. Kubička and L. Kaluz`a, "Deoxygenation of vegetable oils over sulfided Ni, Mo and NiMo catalysts," Appl. Catal. Gen., pp. 199-208, 2010.

[2] Department of Food Science and Technology, "Kandungan Kimia Minyak Jelantah," http://www.Pikiran_rakyat.com (accesed Jul 21, 2021).

[3] R. S. Boyas, Y. Liu, and T. Minowa, "Renewable Diesel Production from the Hydrotreating of Rapeseed Oil with Pt/Zeolite and NiMo/Al2O3 Catalysts," Ind. Eng. Chem. Res., 2011. 
[4] P. Kumar and S. Maity, "Role of NiMo Alloy and Ni Species in the Performance of NiMo/Alumina Catalysts for Hydrodeoxygenation of Stearic Acid: A Kinetic Study," OCS OMEGA Am.

[5] B. Dwiratna and Soebagjo, "Pengembangan Katalis NiMo Alumina Untuk Reaksi Hidrodeoksigenasi Minyak Nabati Menjadi Bioavtur,” J. Energi Dan Lingkung., vol. 11, no. 7, 2015.

[6] L. Chen, H. Li, J. Fu, C. Miao, P. Lv, and Z. Yuan, "Catalytic hydroprocessing of fatty acid methyl esters to renewable alkane fuels over Ni/HZSM-5 catalyst,” Catal. Today, vol. 259, pp. 266-276, Jan 2016, doi: 10.1016/j.cattod.2015.08.023.

[7] Supardi and W. Julianto, "Analisa Pengaruh Viscositas Lumpur Dan Variasi Diameter Pipa Isap Lumpur Terhadap Kapasitas Aliran Pada Mesin Pompa Penyedot Lumpur,” Mek. - J. Tek. MESIN, vol. 2, 2016. 